\title{
Drosophilid assemblages as a bioindicator system of human disturbance in the Brazilian Savanna
}

\author{
Renata Alves da Mata \\ Instituto de Ciências Biológicas/ECO, Universidade de Brasília, 70904-970 Brasília, Brazil \\ Melodie McGeoch \\ Department of Conservation Ecology and Entomology, Centre for Invasion Biology, University of \\ Stellenbosch, Stellenbosch, South Africa \\ Rosana Tidon \\ Department of Conservation Ecology and Entomology, Centre for Invasion Biology, University of \\ Stellenbosch, Stellenbosch, South Africa
}

\begin{abstract}
According to the Convention on Biological Diversity (CBD) the development of bioindicators is extremely necessary to achieve the conservation targets by 2010, and insects are considered an effective group for this goal. Drosophilids are regarded as potential indicators, although this idea remains untested. Therefore, we followed up a protocol to test the drosophilid potential indicator for human disturbance in the Brazilian Savanna, one of the richest and most threatened tropical biomes in the world. Sampling was undertaken in one urban environment and two biological reserves, representing four habitat types (undisturbed gallery forest, disturbed gallery forest, undisturbed savanna, and urban environment). We examined differences in the drosophilid assemblages among habitat types and used the Indicator Value (IndVal) method to point out the indicator species. We also tested the two-stage indicator validation, a protocol recently proposed in the literature, to validate the indicator species for undisturbed gallery forest and savannas, in independent samples. The assemblage variables varied mainly in undisturbed gallery forests, and reflected changes from an undisturbed to a disturbed stage. The IndVal associated with the two-stage protocol showed reliable characteristic species, which are very helpful for diagnostic surveys. Likewise, species that can detect changes in the habitats were also found. We found a set of indicators, which together may be very efficient for both assessing and reflecting a variety of conditions, improving the confidence of the bioindication system, expanding the taxonomic options for bioindicators, and therefore, contributing to the conservation of this region.
\end{abstract}

Keywords: Cerrado biome, Characteristic species, Conservation biology, Detector species, Drosophila, Indicator value, Monitoring, Zaprionus indianus .

\section{Introduction}

The Convention on Biological Diversity (CBD) has established a set of targets to reduce the rate of global biodiversity loss by the year 2010. The development of indicators is among the strategic plans for assessing and monitoring progress toward these conservation targets (United Nations 2002). Despite bioindicators being considered a relatively inexpensive and readily applied approach to assessing environmental condition (Hilty and Merenlender 2000; Dale and Beyeler 2001), bioindicators of disturbance have only been developed for select geographic areas, and using a fairly narrow range of taxa (McGeoch 2007). Ironically, this is particularly true for tropical areas where rates of habitat destruction and biodiversity loss are amongst the highest in the world (Dobson 2005).

The use of species or groups of species to reflect the condition of the environment or a component of biodiversity is far from new. However, only fairly recently have rigorous methodologies been developed and adopted for the identification of bioindicators (McGeoch 1998, 2007), and significant progress in the theoretical and methodological development of bioindicators has recently been made (Landres et al. 1988; Noss 1990; Caro and O'Doherty 1999; Hilty and Merenlender 2000). It is strongly recommended that the 
selection of an indicator must be supported by a sound conceptual framework and follow a scientifically rigorous protocol (Niemi and McDonald 2004). This process should include a clear definition of the bioindication objectives and the scale at which the study is to be conducted, the fulfillment of the taxon in a priori selection criterion, the establishment of the relationships between the indicators and the environment, and the development and testing of hypotheses (McGeoch 1998). In addition, a two-stage process (quantitative identification and verification) is necessary to establish the degree of confidence with which the bioindicator may be applied (McGeoch et al. 2002). The development of a suite of indicator variables (bioindicator system), rather than a single indicator (e.g., one species; Hilty and Merenlender 2000 ) is also recommended to increase the reliability of a bioindication system. These recommendations along with new methodologies are considered a substantial improvement on bioindication selection efficiency and are also likely to increase the successful adoption of bioindicators as management tools. Despite this, to date only a few studies have adopted these recommendation and tested the new methodologies (McGeoch 2007).

Insects are regarded as an effective group for bioindication (Brown 1991, 1997; Kremen et al. 1993; McGeoch 1998; Hilty and Merenlender 2000; Andersen 2004; Samways 2005), and have indeed played an important role in the development and progress in this field of investigation (McGeoch 2007). However, despite their known sensitivity to environmental condition, studies involving insects rarely include a verification of proposed bioindicators, and there remains a narrow range of bioindicator scenarios and geographic regions for which insect bioindicators have been developed (McGeoch 2007). Drosophilids, for example, are potentially good taxa for bioindicators, and certainly no other insect group has been as thoroughly studied (Powell 1997). Although the potential of these flies for bioindication has already been suggested (Parsons 1991, 1995; Saavedra et al. 1995; Ferreira and Tidon 2005) this assumption remains untested.

This paper thus proposes a bioindicator system of human disturbances for the Brazilian Savanna, locally known as Cerrado biome, based on the drosophilid assemblages that inhabit it. The Cerrado is considered one of the 25 hotspots of the world (Myers et al. 2000) due to its high conservation value and the disturbance threat that it faces. It has been extensively transformed into urban and rural environments (Klink and Machado 2005), and only around 2\% of its area is currently protected (Silva et al. 2006). In fact, Cerrado conservation has not reached the status of tropical forests, such as the Amazon and Atlantic Rainforests (Marris 2005). Therefore, studies aiming at developing tools for the diagnosis, monitoring, and management of biodiversity conservation for this biome are urgently needed. Here, we evaluate a protocol proposed in the current literature for testing the potential indicator value of drosophilids for different habitat types in the Cerrado biome. In this context, the main goals of the present study were: (1) to develop a set of indicator variables of undisturbed and disturbed Cerrado habitats, including variables (i) at the assemblage level (richness and abundance of neotropical, exotic, widespread, and narrow range species), and (ii) at the species level (different species); and (2) to test the two-stage indicator validation process (McGeoch et al. 2002) in two contrasting environments of the biome: savannas and gallery forests.

\section{Methods and data}

\section{Study area, sampling, and species identification}

The Cerrado biome is a complex of seasonal savannas that covers most of the interior of Brazil, and is the second largest Brazilian biome, exceeded only by the Amazon Forest (Ratter et al. 1997). This biome, which includes forest, woodland, savanna, and grassland habitats, demonstrates high natural heterogeneity due to the interaction between seasonality, topography, edaphic features, and climate fluctuations (Oliveira and Marquis 2002). Climate in the Cerrado is tropical dry winter (Aw in the Koeppen system) in $95 \%$ of the 
biome, changing to cooler $\mathrm{CW}$ at higher altitudes, and precipitation is highly seasonal, characterized by a well-defined dry season from May to September (Oliveira and Marquis 2002).

Sampling was undertaken in one urban environment and two biological reserves, including four habitat types: undisturbed gallery forests, disturbed gallery forests, undisturbed savannas, and urban environment. The drosophilids were caught using a trap developed to minimize bias in capturing different species of flies attracted to banana baits (Medeiros and Klaczko 1999), monthly, for 12 months (Table 1). The urban environment that was sampled was Brasilia, the capital of Brazil, located in the heart of the Cerrado $\left(15^{\circ} 47^{\prime}\right.$ $\left.\mathrm{S} ; 47^{\circ} 57^{\prime} \mathrm{W}\right)$. Three sites were sampled in this urban environment; in each one-fifteen traps were positioned $10 \mathrm{~m}$ from each other, along a $150 \mathrm{~m}$ transect. Both biological reserves studied here are situated in the outlying neighborhoods of Brasilia. The National Park (NP) is located $10 \mathrm{~km}$ Northwest of Brasilia $\left(15^{\circ} 40^{\prime} \mathrm{S} ; 47^{\circ} 54^{\prime} \mathrm{W}\right)$, and covers an area of 30,000 ha. The Ecological Reserve of IBGE (Instituto Brasileiro de Geografia e Estatística) (RECOR), located $35 \mathrm{~km}$ south of Brasilia ( $15^{\circ} 56^{\prime} \mathrm{S} ; 47^{\circ} 53^{\prime} \mathrm{W}$ ), is part of an environmental protection area that covers 10,000 ha. This last reserve was sampled in two different periods, named RECOR I and RECOR II (Table 1).

Table 1

Characterization of the sampling areas and sites

\begin{tabular}{|c|c|c|c|c|c|c|}
\hline Area & $\begin{array}{l}\text { Sampling } \\
\text { period }\end{array}$ & Habitat types & $\begin{array}{l}\text { Number } \\
\text { of sites }\end{array}$ & $\begin{array}{l}\text { Number } \\
\text { of traps }\end{array}$ & $\begin{array}{l}\text { No. } \\
\text { months } \\
\text { samples }\end{array}$ & Source \\
\hline \multirow{2}{*}{$\begin{array}{l}\text { Brasilia National } \\
\text { Park (NP) }\end{array}$} & \multirow{2}{*}{$\begin{array}{l}07 / 1999 \text { to } \\
06 / 2000\end{array}$} & $\begin{array}{l}\text { Undisturbed } \\
\text { savanna }\end{array}$ & 1 & 10 & 10 & \multirow{2}{*}{$\begin{array}{l}\text { Tidon } \\
(2006)\end{array}$} \\
\hline & & $\begin{array}{l}\text { Undisturbed } \\
\text { gallery forest }\end{array}$ & 1 & 10 & 10 & \\
\hline \multirow{5}{*}{$\begin{array}{l}\text { Ecological } \\
\text { Reserve of IBGE } \\
\text { (RECOR) }\end{array}$} & \multirow{2}{*}{$\begin{array}{l}\text { I. } 07 / 1999 \text { to } \\
06 / 2001\end{array}$} & $\begin{array}{l}\text { Undisturbed } \\
\text { savanna }\end{array}$ & 1 & 10 & 10 & \multirow{2}{*}{$\begin{array}{l}\text { Tidon } \\
(2006)\end{array}$} \\
\hline & & $\begin{array}{l}\text { Undisturbed } \\
\text { gallery forest }\end{array}$ & 1 & 10 & 10 & \\
\hline & \multirow{3}{*}{$\begin{array}{l} \\
\text { II. } 04 / 2001 \\
\text { to } 05 / 2002\end{array}$} & $\begin{array}{l}\text { Undisturbed } \\
\text { savanna }\end{array}$ & 6 & 1 & 6 & \multirow{3}{*}{ Mata (2002) } \\
\hline & & $\begin{array}{l}\text { Undisturbed } \\
\text { gallery forest }\end{array}$ & 3 & 1 & 3 & \\
\hline & & $\begin{array}{l}\text { Disturbed } \\
\text { gallery forest }\end{array}$ & 3 & 1 & 3 & \\
\hline $\begin{array}{l}\text { Brasilia City } \\
\text { (BsB) }\end{array}$ & $\begin{array}{l}09 / 2000 \text { to } \\
08 / 2001\end{array}$ & $\begin{array}{l}\text { Urban } \\
\text { environment }\end{array}$ & 3 & 15 & 45 & $\begin{array}{l}\text { Ferreira and } \\
\text { Tidon } \\
(2005)\end{array}$ \\
\hline
\end{tabular}

In NP and RECOR I, one gallery forest and one savanna-like vegetation (locally known as cerrado sensu stricto or just "cerrado") area were sampled, encompassing four undisturbed sites. Ten traps were placed in each site, positioned $10 \mathrm{~m}$ from each other, along a $100 \mathrm{~m}$ transect. In the RECOR II sample, 12 sites (one trap per site) located in a variety of vegetation forms (disposed at least $100 \mathrm{~m}$ from each other) were classified into three habitat types: (1) undisturbed gallery forest, (2) disturbed gallery forest, and (3) undisturbed savanna.

The drosophilid specimens were identified by identification keys, species description and, in some cases, the male terminalia (Freire-Maia and Pavan 1949; Frota-Pessoa 1954; Val 1982; Vilela 1983, 1992; Vilela and Bächli 1990). 


\section{Drosophilid assemblages as indicators}

First, species were classified into categories based on their biogeographical origin (neotropical or exotic species), and distribution pattern (widespread or narrow range species). The widespread species were those that occurred in all 19 sites; the remaining species were classified as narrow range because they have occurred in <16 sites. The following assemblage variables were analyzed: (1) abundance of neotropical species, (2) abundance of exotics, (3) abundance of narrow range species, (4) abundance of widespread species, (5) neotropical species richness, (6) exotic species richness, and (7) narrow range species richness. Generalized Linear Models (GLM; McCullagh and Nelder 1989) were used to determine significant differences $(\alpha<0.05)$ between assemblage variables among the four habitat types. A Poisson error distribution was assumed for species' richness and abundance variables, and deviance was used as a measure of goodness-of-fit (Collett 1991).

\section{Drosophilid species as indicators}

To identify indicator species characteristic of particular habitats we used the Indicator Value (IndVal) method, developed by Dufrene and Legendre (1997), which combines measurements of the degree of specificity of a species to an ecological state (for instance, a habitat type), and its fidelity (or frequency of occurrence) within that state. It provides an indicator value (IndVal) for each species, as a percentage, based on two criteria:

\section{specificity measure:Aij=Nindividualsij/Nindividualsi}

where Nindividuals ${ }_{\mathrm{ij}}$ is the mean number of species $\mathrm{i}$ across sites of group $\mathrm{j}$, and Nindividuals $\mathrm{i}_{\mathrm{i}}$ is the sum of the mean numbers of individuals of species i over all groups;

\section{fidelity measure: $B_{i j}=N s i t e s i j / N s i t e s j$}

where Nsites ${ }_{\mathrm{ij}}$ is the number of sites in cluster (habitat) $\mathrm{j}$, where species $\mathrm{i}$ is present, and Nsites ${ }_{\mathrm{j}}$ is the total number of sites in that cluster. The percentage indicator value for species $i$ in cluster (habitat) $j$ is then:

IndVal $i j=A_{i j} \times B_{i j} \times 100$

The IndVal represents a significant methodological advance in bioindication studies, and it has various advantages over other analyses used for finding indicator species (McGeoch and Chown 1998). Using this method, it is possible not only to identify characteristic species (Dufrene and Legendre 1997), which are essential for the bioindication surveys, but also detector species, which may be more useful in monitoring changes in environmental condition (McGeoch et al. 2002).

\section{Characteristic species}

Characteristic species are those that have both high specificity and fidelity components of the IndVal measure in a particular habitat type. Therefore, they will have a high percent IndVal. These species make reliable indicator species not only because they are specific to a locality, but also because they have high probability of being sampled in that locality during monitoring and assessment (McGeoch and Chown 1998).

First, we sought to obtain a general overview of the species habitat preferences, and we merged the whole data set into a single matrix (NP + Recor I + Recor II + Brasilia city), classifying the four habitat types as undisturbed gallery forest (gf), undisturbed savanna (sv), disturbed gallery forest (dgf), and urban environment (ur). Species with significant Indicator Values higher than $70 \%$ in a site type were then 
regarded as characteristics species of that particular habitat (see also van Rensburg et al. 1999). Here, the random reallocation procedure was used to test the significance of the IndVal measures for each species (Dufrene and Legendre 1997).

\section{Detector species}

McGeoch et al. (2002) predicted that because characteristic species are highly specific and restricted to a single habitat, they are likely to be vulnerable to change in their preferred habitat state, and may eventually have little value for monitoring. On the other hand, species presenting moderate specificity levels for one habitat state and occurring across a range of habitat states, are more likely to move to adjacent habitats under changing habitat conditions than are highly specific, characteristic species. Thus, such 'detector species' may indicate the direction of change, as well as being of more sustainable use in monitoring (Van Rensburg et al. 1999; McGeoch et al. 2002). Because the Cerrado biome has been intensively transformed by human activities (Klink and Machado 2005), it represents an excellent opportunity for testing the original prediction for detector species. Specifically, when undisturbed forests are subjected to disturbance (i.e., vegetation cut), their canopies become more open, and their environment thus more similar to that of savanna habitat (Pivello and Coutinho 1996). Based on the rationale in McGeoch et al. (2002), under such a change, characteristics species are likely to decline in abundance (and thus in fidelity), whereas detector species abundance is predicted to increase. Thus, drosophilid species with moderate preference for savannas (detector species) would be more likely to invade gallery forests in early stages of their change to a more open state. To test this prediction, we compared the species IndVals among undisturbed gallery forests, disturbed gallery forests, and savannas. Species with moderate preference for savannas were identified as those with IndVals between $50 \%$ and $70 \%$ for this habitat, and between $5 \%$ and $49 \%$ for undisturbed gallery forests. Similarly, detector species for disturbed gallery forests should have IndVals larger than those for undisturbed gallery forests (McGeoch et al. 2002).

We also tested a second prediction, proposed in this study, that assemblages associated with undisturbed habitats would change under increasing disturbance, with some species increasing their preferences for the disturbed habitats, regardless of their moderate preference for a specific habitat type. This prediction was tested by comparing the following habitat types: (1) undisturbed gallery forests $\times$ disturbed gallery forests; (2) undisturbed gallery forests $\times$ urban environments; and (3) undisturbed savannas $\times$ urban environments. For the second prediction, species whose IndVal (>50\%) were higher in disturbed habitats in comparison with undisturbed ones, regardless of their moderate preference for a specific habitat type (savanna), were also identified as possible detector species.

\section{Two-stage indicator validation}

The indicator species identified here were tested following the protocol suggested by McGeoch (1998) and McGeoch et al. (2002). In this approach, after initial bioindicator identification, the proposed bioindicators must be tested by re-sampling the same environment under different temporal or spatial conditions: periods with different climatic conditions, or another place in the region where the bioindicator will be used. Here, the independent samples used were (1) PN plus RECOR I, and (2) RECOR II (Table 1). In this investigation, we included only the undisturbed gallery forests (five sites) and undisturbed savannas (eight sites), using two strategies. In the first one, data of PN plus RECOR I were used to generate the first set of characteristic species for those habitat types, a process called bioindicator identification. They were then tested following the same approach, but now using an independent set of samples, i.e., RECOR II (Table 1), which corresponds to the process of validation. In the second strategy, the complete data set (PN + RECOR I + RECOR II) was used, and the samples were submitted to random selection. The first, randomly selected half of the samples were used to generate a set of characteristic species (identification), and the second 
half was used to test them (validation). It was expected that the most reliable indicators would be identified and re-identified by both strategies. Due to the low number of observations in PN and RECOR I, the criteria for selection in this two-stage process was the frequency with which the species' had IndVals higher than $70 \%$, rather than the significance level. However, the significance level of the IndVals was used to assess the robustness of the indicators.

\section{Results}

Amongst 77,286 individuals analyzed here, 35 neotropical and six exotic species (Drosophila immigrans, D. malerkotliana, D. melanogaster, D. simulans, Scaptodrosophila latifasciaeformis, and Zaprionus indianus) were identified. Six species (D. cardini, D. mercatorum, D. nebulosa, D. simulans, D. sturtevanti, and Z. indianus) occurred at all 19 sites, and were classified as widespread species. The other 35 species were considered narrow range species in the context of the study area (Appendix 1).

\section{Drosophilid assemblages as indicators}

There were significant differences between habitats for two of the four abundance variables, i.e., the abundances of neotropical and narrow range species (Table 2). Drosophilid abundances were generally higher in undisturbed forest than in disturbed forest, although there were no significant differences in the pairwise comparisons (Table 2, Fig. 1a, b). All richness variables varied significantly among habitat types (Table 2). Undisturbed forests had the highest mean richness of both neotropical and narrow range species (Fig. 1c, d). The urban environments had the highest mean richness of exotic species and the lowest neotropical species richness (Fig. 1c, e). 
Fig. 1

Means and 95\% confidence intervals of the variables that showed significant differences among habitat types (significant Wald statistic values). gf, undisturbed gallery forest; dgf, disturbed gallery forest; sv, undisturbed savanna; ur, urban environment. Different letters indicate significant pairwise differences between habitats
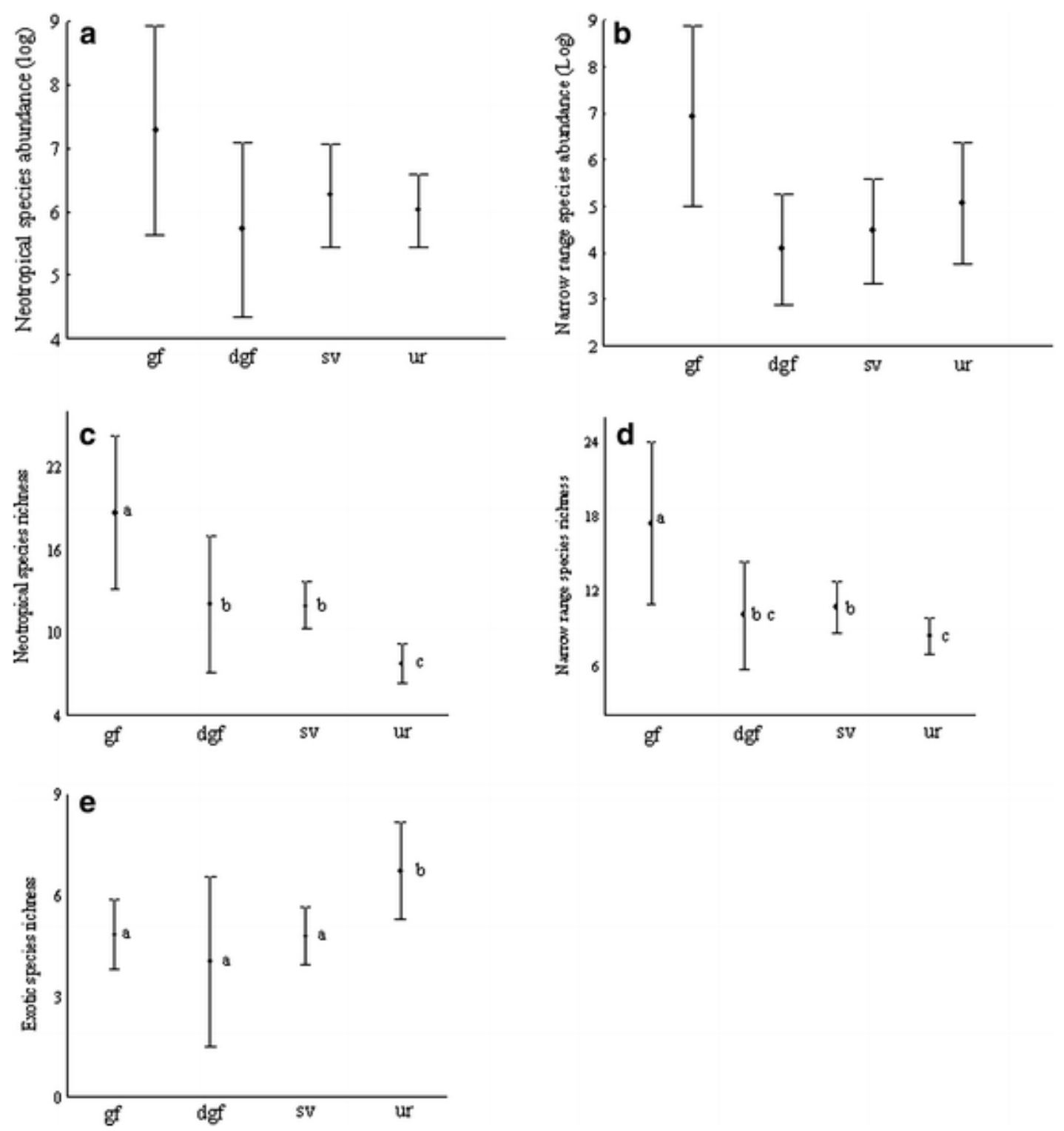

Table 2

Wald's statistics (W) obtained by the Generalized Linear Models (GLM) for seven assemblage variables, indicating which of them show significant differences among habitat types (undisturbed gallery forest; disturbed gallery forest; undisturbed savanna, and urban environment)

Variables df Neotropical Exotic Narrow range Widespread

\begin{tabular}{|l|l|l|l|l|l|}
\hline Abundance (W) & 3,15 & $8.16^{*}$ & 4.46 & $10.57^{*}$ & 4.5 \\
\hline Richness (W) & 3,15 & $38.44^{* *}$ & $12.71^{* *}$ & $23.62^{* *}$ \\
\hline
\end{tabular}

$* \mathrm{P}<0.01$

** $\mathrm{P}<0.001$ 
There were clear differences in the relative abundances of species categories among habitat types (Fig. 2). In terms of biogeographical origin, the undisturbed and disturbed forests were dominated by neotropical species, whereas savannas and urban environments were dominated by exotics (Fig. 2a). In terms of species distribution, the narrow range species (those that occurred in $<16$ sites) dominated undisturbed forests, while the widespread species became increasingly dominant from disturbed forests, to savannas and almost exclusively dominated the urban environments (Fig. 2b).

Fig. 2

Differences in drosophilid assemblage composition among habitat types, showing relative abundance of (a) neotropical and exotic species, and (b) narrow range and widespread species. gf, undisturbed gallery forest; dgf, disturbed gallery forest; sv, undisturbed savanna; ur, urban environment
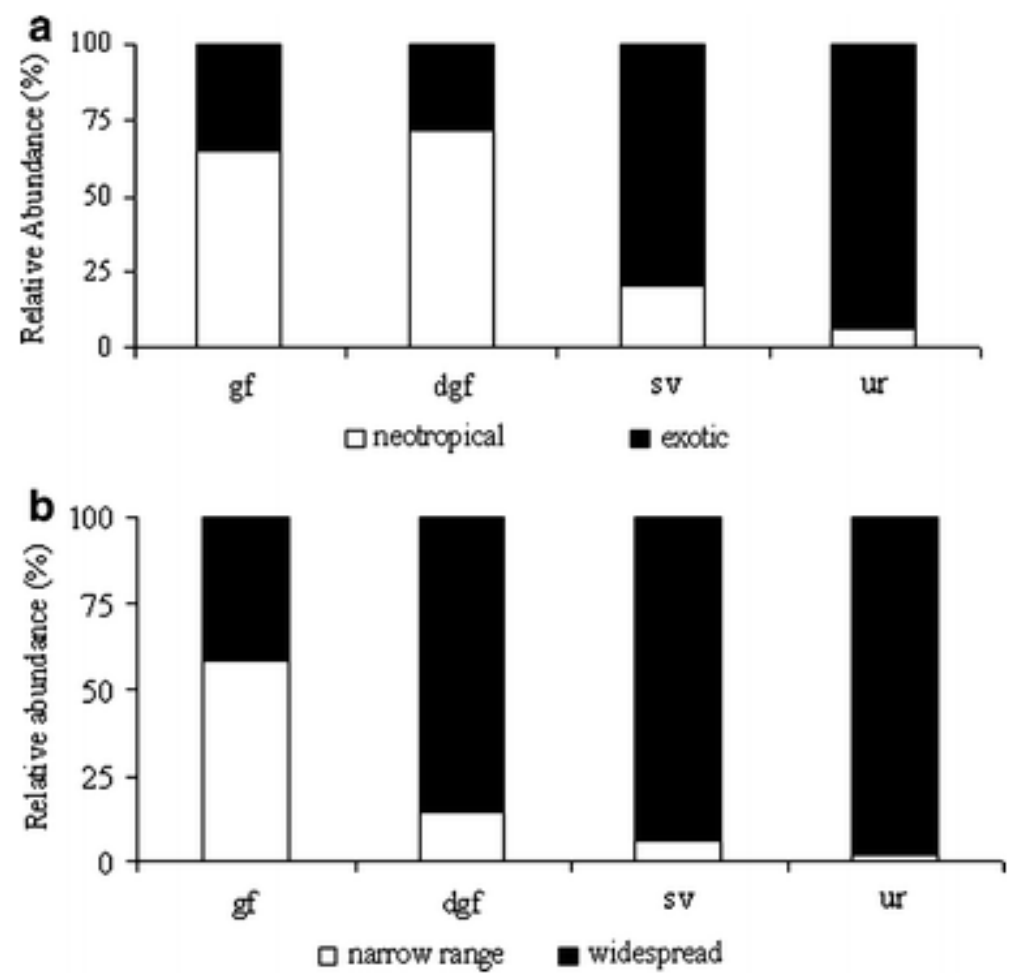

\section{Drosophilid species as indicators}

\section{Characteristic species}

Most of the habitat types, with the exception of disturbed forest, had species with high Indicator Values (Table 3). The majority of the species had highest IndVals for the gallery forests. Among the 24 species that preferred undisturbed gallery forests, five (Drosophila maculifrons, D. mediopunctata, D. ornatifrons, D. paraguayensis, and $\mathrm{D}$. willistoni) had IndVals significantly higher than $70 \%$, and can thus be considered characteristic (indicators) of this habitat. Drosophila cardinoides and D. melanogaster were identified as characteristic species of urban environments, and only D. nigricruria as characteristic of undisturbed savanna (Table 3). The analysis of the relationship between the two components of the IndVal, specificity and fidelity, clearly illustrates that the undisturbed gallery forests had not only more species with high specificity than the other habitat types, but also species filling most regions of the IndVal space (Fig. 3). There were no species with high specificity in disturbed gallery forest (Fig. 3), and only undisturbed gallery forest had species that were truly rare (i.e., highly specific with low fidelity (low occupancy or narrow range; Fig. 3). 
Fig. 3

Relationships between fidelity and specificity (the two components of the Indicator Value) for species in the drosophilid assemblage in four habitat types

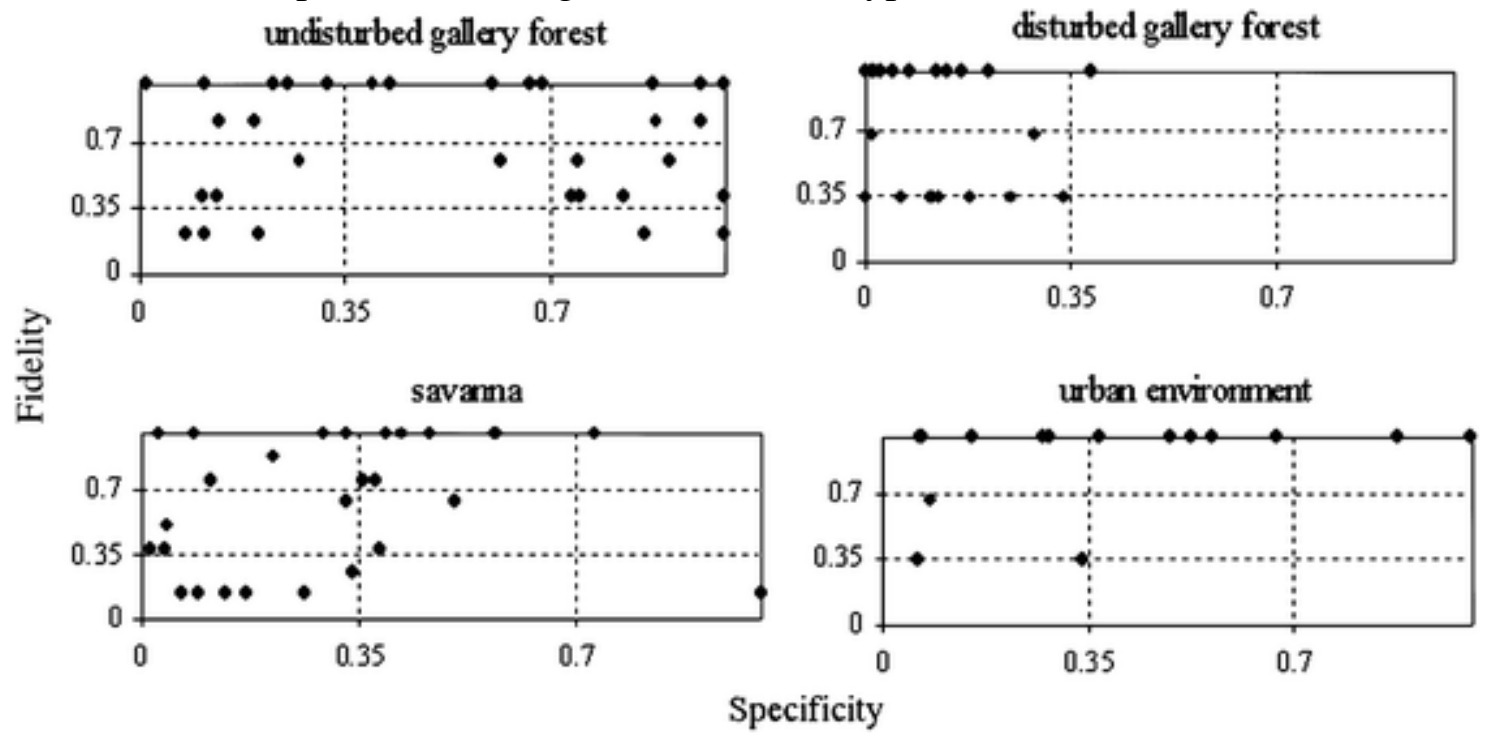

Table 3

Species Indicator Values (IndVal) showing which and how many species prefer each of the four habitats types

\begin{tabular}{|l|l|l|l|}
\hline Species & IndVal (\%) & Species & IndVal (\%) \\
\hline Undisturbed gallery forest & Disturbed gallery forest \\
\hline D. paraguayensis & $100^{*}$ & D. fuscolineata & 38 \\
\hline D. willistoni & $96^{*}$ & & \\
\hline D. ornatifrons & $88^{*}$ & Undisturbed savanna \\
\hline D. maculifrons & $77^{*}$ & D. nigricruria & $73^{*}$ \\
\hline D. mediopunctata & $71^{*}$ & D. hydei & 57 \\
\hline D. malerkotliana & 69 & D. mercatorum & 47 \\
\hline D. immigrans & 67 & D. nebulosa & 40 \\
\hline D. mediostriata & $61^{*}$ & D. cardini & 33 \\
\hline D. schildi & $54^{*}$ & D. fumipennis & 13 \\
\hline D. guaru & 45 & D. medioimpressa & 13 \\
\hline D. sturtevanti & 43 & D. mesostigma & 13 \\
\hline D. ararama & 40 & & \\
\hline D. atrata & 40 & Urban environment \\
\hline D. bandeirantorum & 40 & D. melanogaster & $100^{*}$ \\
\hline D. polymorpha & 40 & D. cardinoides & $87^{*}$ \\
\hline D. neocardini & 33 & D. simulans & $67^{*}$ \\
\hline D. bocainensis & 30 & Z. indianus & 56 \\
\hline D. austrosaltans & 29 & D. prosaltans & $53^{*}$ \\
\hline D. arauna & 20 & S. latifasciaeformis & 53 \\
\hline D. neoguaramunu & 20 & D. busckii & 49 \\
\hline
\end{tabular}




\begin{tabular}{|l|l|l|l|}
\hline Species & IndVal (\%) & Species & IndVal (\%) \\
\hline D. onca & 20 & D. paranaensis & 11 \\
\hline D. paramediostriata & 20 & & \\
\hline D. pallidipennis & 17 & & \\
\hline D. aragua & 16 & & \\
\hline
\end{tabular}

$* \mathrm{P}<0.05$

\section{Detector species}

Drosophila hydei presented low specificity for undisturbed gallery forest (IndVal $=2 \%$ ), moderate for savannas (IndVal $=61 \%$ ), and an intermediate value (between undisturbed forest and savanna) in disturbed forests (IndVal $=20 \%$ ). Therefore, only this species matched the original conditions for detector of changes from undisturbed to disturbed gallery forest, since it was more prevalent in an intermediate habitat (disturbed gallery forests) than in the less preferred habitat stage (undisturbed forest), and still had a moderate preference for the other habitat stage (savanna) (Table 4). Besides D. hydei, another seven species (D. busckii, D. immigrans, D. mercatorum, D. prosaltans, D. simulans, Scaptodrosophila latifasciaeformis, and Zaprionus indianus) met the second prediction for detector species of change from undisturbed to disturbed habitats. Those species increased their preferences (or IndVals) from undisturbed forests and savannas to urban environments, regardless of showing a moderate preference for savannas, as expected by the original prediction (Table 4).

Table 4

Indicator values of those species that matched the criteria for detector species for each comparison. (1) Undisturbed gallery forest (gf) $\times$ disturbed gallery forest (dgf) $\times$ undisturbed savanna (sv); (2) undisturbed gallery forest $\times$ disturbed gallery forest; (3) undisturbed gallery forest $\times$ urban environment (ur); (4) undisturbed savanna $\times$ urban environment

\begin{tabular}{|c|c|c|c|c|}
\hline Comparison & Species & Inc & Val & $(\%)$ \\
\hline 1 & & gf & $\operatorname{dgf}$ & SV \\
\hline 1 & D. hydei & 2 & 20 & 61 \\
\hline & & gf & dgf & \\
\hline 2 & D. hydei & 4 & 52 & \\
\hline & & gf & ur & \\
\hline & D. busckii & 9 & 79 & \\
\hline & D. mercatorum & 23 & 77 & \\
\hline 3 & D. prosaltans & 22 & 73 & \\
\hline & D. simulans & 25 & 75 & \\
\hline & S. latifasciaeformis & 7 & 83 & \\
\hline & Z. indianus & 2 & 98 & \\
\hline & & SV & ur & \\
\hline & D. busckii & 33 & 57 & \\
\hline 4 & D. immigrans & 4 & 88 & \\
\hline & D. prosaltans & 13 & 83 & \\
\hline & D. simulans & 11 & 89 & \\
\hline
\end{tabular}




\begin{tabular}{|l|l|l|l|l|}
\hline Comparison & Species & \multicolumn{2}{|l|}{ IndVal (\%) } \\
\hline & S. latifasciaeformis & 30 & 59 & \\
\hline Z. indianus & 43 & 57 \\
\hline
\end{tabular}

\section{Two-stage indicator validation}

Although several species were identified initially as characteristic species of undisturbed gallery forests and savannas, only five were re-identified as characteristics species when testing using the two approaches (independent data set and random data subsampling; Table 5). Drosophila ornatifrons, D. paraguayensis, and $\mathrm{D}$. willistoni emerged as robust characteristic species of gallery forests, and D. mercatorum and $\mathrm{Z}$. indianus of savanna environments (Table 5).

\section{Table 5}

Species identified as characteristic of undisturbed gallery forests and undisturbed savannas, in the two-stage identification process for RECOR I/NP and RECOR II data sets

\begin{tabular}{|c|c|c|c|}
\hline \multirow{2}{*}{$\begin{array}{l}\text { Approach } \\
\text { Independent } \\
\text { sample }\end{array}$} & \multirow[t]{2}{*}{ Data set } & \multicolumn{2}{|l|}{ Habitat types } \\
\hline & & $\begin{array}{l}\text { Undisturbed gallery forest } \\
(\mathrm{n}=2)\end{array}$ & Savanna $(\mathrm{n}=2)$ \\
\hline & \multirow{4}{*}{$\begin{array}{l}\text { RECOR I/NP } \\
\text { (identification) }\end{array}$} & D. bocainensis & D. busckii \\
\hline & & D. fuscolineata & D. nebulosa \\
\hline & & D. guaru & $\begin{array}{l}\text { S. } \\
\text { laficasciaeformis }\end{array}$ \\
\hline & & D. maculifrons & \\
\hline & \multirow{5}{*}{$\begin{array}{l}\text { RECOR II } \\
\text { (validation) }\end{array}$} & $(n=3)$ & $(\mathrm{n}=6)$ \\
\hline & & D. mediostriata & D. cardini* \\
\hline & & D. prosaltans & D. nigricruria* \\
\hline & & & D. polymorpha* \\
\hline & & & D. simulans \\
\hline & \multirow{4}{*}{$\begin{array}{l}\text { RECOR I/NP and } \\
\text { RECOR II }\end{array}$} & D. immigrans* & D. hydei* \\
\hline & & D. ornatifrons* & D. mercatorum* \\
\hline & & D. paraguayensis* & Z. indianus* \\
\hline & & D. willistoni* & \\
\hline \multirow[t]{8}{*}{$\begin{array}{l}\text { Random } \\
\text { selection }\end{array}$} & & $\begin{array}{l}\text { Undisturbed gallery forest } \\
(n=3)\end{array}$ & Savanna $(\mathrm{n}=4)$ \\
\hline & \multirow{7}{*}{$\begin{array}{l}\text { Selection I } \\
\text { (identification) }\end{array}$} & D. immigrans & \\
\hline & & D. maculifrons & \\
\hline & & D. malerkotliana & \\
\hline & & D. mediopunctata* & \\
\hline & & D. mediostriata & \\
\hline & & D. polymorpha & \\
\hline & & D. schildi* & \\
\hline
\end{tabular}




\begin{tabular}{|c|c|c|c|}
\hline \multirow[t]{2}{*}{ Approach } & \multirow{3}{*}{ Data set } & \multicolumn{2}{|l|}{ Habitat types } \\
\hline & & D. simulans & \\
\hline & & D. sturtevanti & \\
\hline & \multirow{10}{*}{$\begin{array}{l}\text { Selection II } \\
\text { (validation) }\end{array}$} & $(\mathrm{n}=2)$ & $(n=4)$ \\
\hline & & D. prosaltans & D. busckii \\
\hline & & & D. cardini \\
\hline & & & D. hydei \\
\hline & & & D. malerkotliana \\
\hline & & & D. nebulosa \\
\hline & & & D. nigricruria \\
\hline & & & D. simulans \\
\hline & & & D. sturtevanti \\
\hline & & & S. latifasciaeformis \\
\hline & \multirow{3}{*}{ Selection I and II } & D. ornatifrons & D. mercatorum \\
\hline & & D. paraguayensis* & Z. indianus \\
\hline & & D. willistoni & \\
\hline
\end{tabular}

The underlined species were re-identified as characteristics species when testing using the two approaches (independent data set and random data subsampling), and therefore, they emerged as robust characteristic species

\section{Discussion}

The present survey has formally tested the potential indicator of drosophilids in the Cerrado biome, by following up a methodology that associates the Indicator Value method (Dufrene and Legendre 1997) and the two-stage indicator validation (McGeoch et al. 2002). A set of reliable indicator variables were found at both assemblage and species levels, that together, are likely to be efficient in reflecting a variety of ecological conditions. The undisturbed forests supported the greatest number and dominance of neotropical and narrow range species, while the exotic and widespread species dominated the disturbed forests, savannas, and urban environment. Therefore, evaluating changes in the raw and relative abundances, as well as in the richness of different species categories, provides a good overview of the alterations in drosophilid assemblages in different habitats. This kind of information can be useful not only in diagnostic surveys, but also in monitoring the incidence of disturbance over time.

At the species level, most of species that showed specificity for undisturbed forests did not reach the status of indicator because the fidelity component of the IndVal was not sufficiently high (Dufrene and Legendre 1997). Although these species demonstrated preference for undisturbed forests, many of them being even exclusive from these habitats, they were only found in one or few sites, and in very low densities, which means that it will be extremely difficult and improbable to find these species in other sites or investigations (McGeoch and Chown 1998). On the other hand, five reliable indicators emerged from the identification and testing process for undisturbed gallery forests (Drosophila paraguayensis, D. ornatifrons, and D. willistoni) and savannas (D. mercatorum and Zaprionus indianus) as they showed high frequency of occurrence (fidelity), and preference (specificity) for these habitats across independent data sets (see also Tidon 2006). Saavedra et al. (1995) have already suggested D. willistoni as an indicator of conserved Atlantic Forest environments. Therefore, due to their high reliability and specificity to particular habitats, 
such characteristic species are very useful in diagnostic surveys. D. cardinoides and D. melanogaster emerged as indicators of urban environments; however, they could not be validated due to the absence of independent data sets for these environments.

Because Drosophila hydei was more prevalent in intermediate habitat (disturbed gallery forests) than in the less preferred habitat stage (undisturbed forest), but still had a moderate preference for the other habitat stage (savanna), it was the only species that matched the original prediction for detector species (McGeoch et al. 2002). Besides this one, other seven species also increased their preferences for disturbed environments, when compared to the undisturbed stage, but they did not have an intermediate preference for savannas as expected by the original prediction. Nonetheless, these species clearly demonstrated a change in habitat between the two stages (from undisturbed to disturbed forest), and for this reason, they were also regarded as detector species. Detector species are a useful class of ecological bioindicator, since they are indicative not only of the changes in habitat conditions, but also of the direction of such changes, and therefore, they are very useful in monitoring surveys. Characteristic and detector species provide complementary information with higher information content and reliability than either group on this own (McGeoch et al. 2002). The use of a group of indicator variables, which are complementary, is considered critical and indispensable for bioindication studies. This approach will minimize the dependence on an individual taxon and improve the system reliability, since the conclusions will be based on a greater variety of measures (Hilty and Merenlender 2000).

The present results corroborate that the IndVal method (Dufrene and Legendre 1997) associated with twostage indicator validation correspond to an excellent tool for developing bioindicators. Besides all of the advantages previously discussed, the IndVal has also supplied essential information on drosophilid species preferences, subdividing them into different assemblages, typical to the habitat types and presence of disturbance. The sensitivity of the method in classifying the assemblages was very useful considering the large heterogeneity of habitats in the Cerrado. Describing how the assemblages are organized, and at which scale, is a fundamental step for understanding the mechanisms involved on their regulation (Dufrene and Legendre 1997). Moreover, the IndVal method takes into account the identity of each species, and therefore produces qualitative rather than the quantitative results produced by other diversity indexes. Such qualitative approach is extremely suitable for studies related to biodiversity conservation.

McGeoch et al. (2002) have advocated that the two-stage indicator validation is essential for all studies concerned with indicator development and the present study confirm this recommendation. A large number of species were identified as characteristic of a particular habitat, but only those that were validated by the two approaches were recognized as reliable indicators. Species that were initially identified as indicator but were not validated were then considered as unreliable. By using this method, the degree of reliability of the final set of identified indicators was greatly improved and refined. It is highly recommended that future studies validate the other findings of this study, such as the characteristic species of urban environments and the detector species.

\section{Drosophilids as indicators of human change on the Cerrado habitats}

The potential of drosophilid species as bioindicators was formally tested and confirmed. A set of criteria for the selection of ecological indicators has been established in literature in the last 20 years (Landres et al. 1988; Noss 1990; McGeoch 1998; Caro and O'Doherty 1999; Hilty and Merenlender 2000; Dale and Beyeler 2001; Niemi and McDonald 2004), and in general, drosophilids fulfil many of these criteria. These organisms are regarded as excellent biological models for ecological research because they are small, numerous, easily collected and manipulated, and relatively cheap to maintain (Powell 1997; Brookes 2001). Consequently, they have been broadly studied, and there is a large amount of reliable and available 
information about them (Bächli 2007; Grumbling and Strelets 2007). Currently, this family includes more than 3,500 described species (Bächli 2007). Some species, that exploit a very broad range of plants, evolved as human commensals, spreading around the world. Other species exploit a very narrow range of breeding sites, being extremely specialized and restricted to a single type of environment (Powell 1997). As a result, they are widespread around the world, being found in all biogeographical regions, and occurring in a variety of habitat types, from pristine to urban environments (Wheeler 1981, 1986). Many species are also closely associated to environmental variables, being extremely sensitive to changes on the habitats conditions (Karan et al. 1998; Jenkins and Hoffmann 2001; Van Klinken and Walter 2001; Avondet et al. 2003; Hoffmann et al. 2003). These features associated to a short life cycle allow these organisms to be anticipatory, as well as to be used in monitoring changes in habitats conditions. Moreover, associations between drosophilids and the Cerrado habitats have already been suggested. Even though the family is widely distributed in the biome, the assemblages vary substantially in abundance and composition between forests and savannas, and across seasons (Tidon 2006); along an urban gradient (Ferreira and Tidon 2005); and also reflecting the effects of human disturbances at a local scale (Mata 2002).

The present evaluation of the drosophilid species in Cerrado suggests that the undisturbed gallery forests are extremely special habitats in the Cerrado biome because they were the richest studied habitat, and were also most unique, given the predominance of rare species. Rare species are often the focus of conservation strategies due to their higher vulnerability to extinction (IUCN 2007). In contrast, abundant and widespread species that showed low preference for undisturbed forests were more abundant in the disturbed stage. The majority of species of several taxa also demonstrates preference or is associated with gallery forests, for instance, plants (Mendonça et al. 1998), mammals (Redford and Fonseca 1986), birds (Silva 1995), butterflies (Brown 2000), and wasps (Diniz and Kitayama 1998). Therefore, although gallery forests occupy $<10 \%$ of all Cerrado extension, these habitats are extremely important to Cerrado biodiversity (Oliveira and Marquis 2002). However, these habitats have intensively been substituted by human environments, what causes habitat loss and fragmentation (Silva et al. 2006), and once transformed, regeneration to an original condition is extremely improbable (Pivello and Coutinho 1996). If such disturbances persist for a long time, they will probably cause an irreversible impoverishment in the regional biota of this rich ecosystem. For instance, the original different drosophilid assemblages from forests and savannas can become more similar, since abundant and widespread species that dominate the savannas invade gallery forests when they are disturbed.

In conclusion, the results presented here provided information that can be extremely helpful to develop and improve management for the complex forest-savanna mosaic present in the Cerrado biome. In addition, the bioindicator system proposed represents a novel option, complementing the still few surrogate taxa used in this biome, generally plants and vertebrates, that alone, provide only a limited view of the environment. These indicators may be very helpful to reflect disturbance incidence at the beginning, in monitoring and restoring conservation programs and to refine the selection, planning, and management of the reserve areas. Nevertheless, it can help in clarifying mechanisms by which human activities affect biodiversity and facilitate improved projections about what might happen in the future. Studies intending to test this system, and to validate some of the results found here by incorporating other habitat types, using standardized methodology, independent samplings (at spatial and temporal scales), as well as measuring environmental variables, are essential to continuously improve its reliability and robustness. 


\section{Appendix 1}

Abundance of drosophilid species identified in this study and number of sites in which they occurred

\begin{tabular}{|c|c|c|}
\hline Species & Abundance & Sites \\
\hline Zaprionus indianus ${ }^{a}$ Gupta, 1970 & 32,110 & 19 \\
\hline Drosophila simulans ${ }^{\text {a }}$ Sturtevant, 1919 & 19,900 & 19 \\
\hline D. willistoni Sturtevant, 1916 & 10,574 & 16 \\
\hline D. sturtevanti Duda, 1927 & 4,402 & 19 \\
\hline $\begin{array}{l}\text { D. mercatorum Patterson \& Wheeler, } \\
1942\end{array}$ & 2,885 & 19 \\
\hline D. nebulosa Sturtevant, 1916 & 1,719 & 19 \\
\hline D. cardini Sturtevant, 1916 & 1,276 & 19 \\
\hline D. malerkotliana ${ }^{\text {a }}$ Parshad \& Paika, 1964 & 1,173 & 16 \\
\hline $\begin{array}{l}\text { D. polymorpha Dobzanhsky \& Pavan, } \\
1943\end{array}$ & 807 & 16 \\
\hline D. immigrans ${ }^{\text {a }}$ Sturtevant, 1921 & 680 & 14 \\
\hline $\begin{array}{l}\text { Scaptodrosophila latifasciaeformis }{ }^{\text {a }} \\
\text { Duda, } 1940\end{array}$ & 436 & 12 \\
\hline D. paraguayensis Duda, 1927 & 278 & 5 \\
\hline D. ornatifrons Duda, 1927 & 213 & 12 \\
\hline D. hydei Sturtevant, 1921 & 167 & 12 \\
\hline $\begin{array}{l}\text { D. cardinoides Dobzanhsky \& Pavan, } \\
1943\end{array}$ & 142 & 7 \\
\hline $\begin{array}{l}\text { D. nigricruria Patterson \& Mainland, } \\
1943\end{array}$ & 90 & 13 \\
\hline D. prosaltans Duda, 1927 & 80 & 16 \\
\hline D. busckii ${ }^{\text {a }}$ Coquillet, 1901 & 77 & 11 \\
\hline D. maculifrons Duda, 1927 & 50 & 7 \\
\hline
\end{tabular}




\begin{tabular}{|c|c|c|}
\hline Species & Abundance & Sites \\
\hline D. fuscolineata Duda, 1925 & 33 & 6 \\
\hline D. mediostriata Duda, 1925 & 31 & 11 \\
\hline $\begin{array}{l}\text { D. mediopunctata Dobzhansky \& Pavan, } \\
1943\end{array}$ & 27 & 5 \\
\hline D. austrosaltans Spassky, 1957 & 22 & 3 \\
\hline D. neocardini Streisinger, 1946 & 20 & 3 \\
\hline D. aragua Vilela \& Pereira, 1982 & 16 & 7 \\
\hline D. paranaensis Barros, 1950 & 15 & 5 \\
\hline D. atrata Burla \& Pavan, 1953 & 10 & 2 \\
\hline D. bocainensis Pavan \& Cunha, 1947 & 9 & 4 \\
\hline D. schildi Malloch, 1924 & 7 & 4 \\
\hline D. mesostigma Frota-Pessoa, 1954 & 7 & 1 \\
\hline D. guaru Dobzanhsky \& Pavan, 1943 & 6 & 4 \\
\hline $\begin{array}{l}\text { D. pallidipennis Dobzanhsky \& Pavan, } \\
1943\end{array}$ & 5 & 2 \\
\hline D. melanogaster ${ }^{a}$ Meigen, 1830 & 4 & 3 \\
\hline $\begin{array}{l}\text { D. bandeirantorum Dobzhansky \& } \\
\text { Pavan, } 1943\end{array}$ & 4 & 2 \\
\hline D. onca Dobzanhsky \& Pavan, 1943 & 3 & 1 \\
\hline D. ararama Pavan \& Cunha, 1947 & 2 & 2 \\
\hline D. arauna Pavan \& Nacrur, 1950 & 2 & 1 \\
\hline D. fumipennis Duda, 1925 & 1 & 1 \\
\hline D. medioimpressa Frota-Pessoa, 1954 & 1 & 1 \\
\hline D. neoguaramunu Frydenberg, 1956 & 1 & 1 \\
\hline
\end{tabular}




\begin{tabular}{|l|l|l|}
\hline Species & Abundance & Sites \\
\hline \begin{tabular}{l|l|l|} 
D. paramediostriata Townsend \& \\
Wheeler, 1955
\end{tabular} & 1 & 1 \\
\hline Total & 77,286 & 19 \\
\hline
\end{tabular}

${ }^{\mathrm{a}}$ Exotic species

\section{References}

Andersen AN (2004) Use of terrestrial invertebrates for biodiversity monitoring in Australia rangelands, with particular reference to ants. Aust Ecol 29:87-92.

Avondet JL, Blair RB, Berg DJ et al (2003) Drosophila (Diptera: Drosophilidae) response to changes in ecological parameters across an urban gradient. Environ Entomol 32:347-358

Bächli G (2007) TaxoDros: the database on taxonomy of Drosophilidae. http://www.taxodros.unizh.ch/. Accessed 16 Oct 2007

Brookes M (2001) Fly: an experimental life. Weidenfeld \& Nicolson, London, UK

Brown KS (1991) Conservation of neotropical environments: insects as indicators. In: Collins NM, Thomas JA (eds) The conservation of insects and their habitats. Academic Press, London

Brown KS (1997) Diversity, disturbance, and sustainable use of neotropical forests: insects as indicators for conservation monitoring. J Insect Conserv 1:25-42.

Brown KS (2000) Insetos indicadores da história, composição, diversidade e integridade de Matas Ciliares. In: Rodrigues RR, Leitão Filho HF (eds) Matas Ciliares: conservação e recuperação. EDUSP, São Paulo

Caro TM, O’Doherty G (1999) On the use of surrogate species in conservation biology. Conserv Biol 13:805-814.

Collett D (1991) Modeling binary data. Chapman \& Hall, London, UK

Dale VH, Beyeler SC (2001) Challenges in the development and use of ecological indicators. Ecol Indic 1:1-9.

Diniz IR, Kitayama K (1998) Seasonality of vespid species (Hymenoptera : Vespidae) in a central Brazilian cerrado. Rev Biol Trop 46:109-114

Dobson A (2005) Monitoring global rates of biodiversity change: challenges that arise in meeting the convention on Biological Diversity (DBD) 2010 goals. Philos Trans R Soc B 360:229-241.

Dufrene M, Legendre P (1997) Species assemblages and indicator species: the need for a flexible asymmetrical approach. Ecol Monogr 67:345-366

Ferreira L, Tidon R (2005) Colonizing potential of Drosophilidae (Insecta, Diptera) in environments with different grades of urbanization. Biodivers Conserv 14:1809-1821.

Freire-Maia A, Pavan C (1949) Introdução ao estudo da drosófila. Cultus 1:3-66 
Frota-Pessoa O (1954) Revision of the tripunctata group of Drosophila with description of fifteen new species (Drosophilidae, Diptera). Archos Mus Parana 10:253-304

Grumbling G, Strelets V (2007) FlyBase: anatomical data, images and queries. Nucleic Acids Res. http://www.flybase.org/34. Accessed 16 Oct 2007

Hilty J, Merenlender A (2000) Faunal indicator taxa selection for monitoring ecosystem health. Biol Conserv 92:185-197.

Hoffmann AA, Hallas RJ, Dean JA et al (2003) Low potential for climatic stress adaptation in a rainforest Drosophila species. Science 301:100-102.

IUCN (2007) IUCN Red List of threatened species. http://www.iucnredlist.org. Accessed 16 Oct 2007

Jenkins NL, Hoffmann AA (2001) Variation in morphological traits and trait asymmetry in field Drosophila serrata from marginal populations. J Evol Biol 13:113-130.

Karan D, Dahiya N, Munjal A et al (1998) Desiccation and starvation tolerance of adult Drosophila: opposite latitudinal clines in natural populations of three different species. Evolution 52:825-831.

Klink CA, Machado RB (2005) Conservation of the Brazilian Cerrado. Conserv Biol 19:707-713.

Kremen C, Colwell RK, Erwin TL et al (1993) Terrestrial arthropod assemblages-their use in conservation planning. Conserv Biol 7:796-808.

Landres PB, Verner J, Thomas JW (1988) Ecological uses of vertebrate indicator species-a critique. Conserv Biol 2:316-328.

Marris E (2005) Conservation in Brazil: the forgotten ecosystem. Nature 437:944-945.

Mata RA (2002) Drosofilídeos (Diptera, Insecta) como indicadores do estado de perturbação do Cerrado. Dissertation, Universidade de Brasília

McCullagh P, Nelder JA (1989) Generalized Linear Models. Chapman \& Hall, London, UK

McGeoch MA (1998) The selection, testing and application of terrestrial insects as bioindicators. Biol Rev Cambridge Philos Soc 73:181-201.

McGeoch MA (2007) Insects and bioindication: theory and progress. In: Stewart AJA, Lewis OT, New TR (eds) Insect conservation biology. CABI Publishing, London

McGeoch MA, Chown SL (1998) Scaling up the value of bioindicators. Trends Ecol Evol 13:4647.

McGeoch MA, Van Rensburg BJ, Botes A (2002) The verification and application of bioindicators: a case study of dung beetles in a savanna ecosystem. J Appl Ecol 39:661-672.

Medeiros HF, Klaczko LB (1999) A weakly biased Drosophila trap. Drosoph Inf Serv 82:100-102 
Mendonça RC, Felfili JM, Walter BMT et al (1998) Flora vascular do cerrado. In: Sano SM, Almeida AM (eds) Cerrado: Ambiente e Flora. Empresa Brasileira de Pesquisa Agropecuária, Planaltina

Myers N, Mittermeyer RA, Mittermeyer CG et al (2000) Biodiversity spots for conservation priorities. Nature 403:853-858.

Niemi GJ, McDonald ME (2004) Application of ecological indicators. Annu Rev Ecol Evol Syst 35:89-111.

Noss RF (1990) Indicators for monitoring biodiversity: a hierarchical approach. Conserv Biol 4:355-364.

Oliveira PS, Marquis RJ (2002) The Cerrados of Brazil. Ecology and natural history of a neotropical Savanna. Columbia University Press, New York

Parsons PA (1991) Biodiversity conservation under global climatic-change-the insect Drosophila as a biological indicator. Glob Ecol Biogeogr 1:77-83.

Parsons PA (1995) Evolutionary response to drought stress-conservation implications. Biol Conserv 74:21-27.

Pivello VR, Coutinho LM (1996) A qualitative successional model to assist in the management of Brazilian cerrados. For Ecol Manage 87:127-138.

Powell JR (1997) Progress and prospects in evolutionary biology: the Drosophila Model. Oxford University Press, New York

Ratter JA, Ribeiro JF, Bridgewater S (1997) The Brazilian cerrado vegetation and threats to its biodiversity. Ann Bot 80:223-230.

Redford KH, Fonseca GAB (1986) The role of gallery forest in the zoogeography of the cerrado's non-volant mammalian fauna. Biotropica 18:126-135.

Saavedra CCR, Callegari-Jacques SM, Napp M et al (1995) A descriptive and analytical study of 4 neotropical drosophilid communities. J Zool Syst Evol Res 33:62-74

Samways MJ (2005) Insect diversity conservation. Cambridge University Press, Cambridge

Silva JMC (1995) Birds of the Cerrado Region, South America. Steenstrupia 21:69-92

Silva JF, Farinas MR, Felfili JM et al (2006) Spatial heterogeneity, land use and conservation in the cerrado region of Brazil. J Biogeogr 33:536-548.

Tidon R (2006) Relationships between drosophilids (Diptera, Drosophilidae) and the environment in two contrasting tropical vegetations. Biol J Linn Soc 87:233-248.

United Nations (2002) Report of the World Summit on Sustainable Development. A/CONF.199/20. Johannesburg

Val FC (1982) The male genitalia of some Neotropical Drosophila: notes and illustrations. Pap Avul Dep Zool Sec Agric 34:309-347 
Van Klinken RD, Walter GH (2001) Subtropical drosophilids in Australia can be characterized by adult distribution across vegetation type and by height above forest floor. J Trop Ecol 17:705-718

Van Rensburg BJ, McGeoch MA, Chown SL et al (1999) Conservation of heterogeneity among dung beetles in the Maputaland Centre of Endemism, South Africa. Biol Conserv 88:145-153.

Vilela CR (1983) A revision of the Drosophila repleta species group (Diptera, Drosophilidae). Rev Bras Entomol 27:1-114

Vilela CR (1992) On the Drosophila tripunctata species group (Diptera, Drosophilidae). Rev Bras Entomol 36:197-221

Vilela CR, Bächli G (1990) Taxonomic studies on neotropical species of seven genera of Drosophilidae (Diptera). Mitt Schweiz Ent Ges 63:1-332

Wheeler MR (1981) The Drosophilidae: a taxonomic overview. In: Ashburner M, Carson HL, Thompson JN Jr (eds) Genetics and biology of Drosophila. Academic Press, New York

Wheeler MR (1986) Additions to the catalog of the world's Drosophilidae. In: Ashburner M, Carson HL, Thompson JN Jr (eds) Genetics and biology of Drosophila. Academic Press, New York 